\title{
National Heart, Lung, and Blood Institute
}

National Cancer Institute

\section{Source}

National Cancer Institute. National Heart, Lung, and Blood Institute. NCI Thesaurus.

Code C82613.

An institute within the National Institutes of Health that provides global leadership for a research, training, and education program to promote the prevention and treatment of heart, lung, and blood diseases and enhance the health of all individuals so that they can live longer and more fulfilling lives. 